They were also less familiar with its use for OA treatment, less likely to believe in its efficacy, and less willing to use it as treatment for OA. Improving patient knowledge and attitudes about exercise may increase utilisation of this OA treatment and help reduce ethnic differences in OA outcomes.

Disclosure of Interest: E. Vina: None declared, D. Ran: None declared, M. Hannon: None declared, C. Kwoh Grant/research support from: Abbvie, EMD Serono, Consultant for: Astellas, EMD Serono, Thusane, Express Scripts, Novartis DOI: 10.1136/annrheumdis-2018-eular.3571

\section{THU0650 EARLY HELP SEEKING OR SELF-MANAGEMENT: A QUANTITATIVE ASSESSMENT IN THE CONTEXT OF RHEUMATOID ARTHRITIS}

G. Simons ${ }^{1}$, J. Belcher ${ }^{2}$, K. Kumar ${ }^{1}$, M. Falahee ${ }^{1}$, C.D. Mallen ${ }^{2}$, R.J. Stack ${ }^{1,3}$, K. Raza ${ }^{1} .{ }^{1}$ University of Birmingham, Birmingham; ${ }^{2}$ Keele University, Keele; ${ }^{3}$ Nottingham Trent University, Nottingham, UK

Background: Rheumatoid arthritis (RA) should be treated with DMARDs in its earliest stages to reduce the likelihood of permanent joint damage and disability ${ }^{1}$. This therapeutic window is often missed. One important cause is delayed help seeking by patients themselves ${ }^{2}$. Qualitative work with members of the public has previously identified a number of potential causes for this delay ${ }^{3}$.

Objectives: To quantify and extend the findings of existing qualitative research investigating factors which impact on speedy help seeking for symptoms of RA Methods: A survey of members of the public without a diagnosis of inflammatory arthritis assessed the speed with which they would seek medical attention if they were to experience symptoms of RA (stiffness, pain and joint swelling). It explored factors which might impact on the speed with which help would be sought, including: self-management of symptoms; barriers to and drivers of help seeking and information seeking.

Results: 1088 people (788 females; 9 undisclosed) aged between 18 and 96 years completed the survey. $48 \%$ indicated that they would seek help quickly for RA symptoms, however $63 \%$ would delay seeing their GP in order to try to selfmanage the symptoms. Most intended to self-manage with over the counter medication (e.g. ibuprofen), massaging the joint or exercising. Barriers endorsed included difficulty getting a GP appointment (39\%); fear of wasting the GP's time (34\%) and being busy with family/work (37\%). Drivers (>90\%) included worsening of symptoms, inability to work, struggling to do usual activities, symptoms spreading to other parts of the body or inability to self-manage symptoms. Most participants would seek out information prior to seeking medical attention for the symptoms. Sources of information frequently endorsed were: Internet (74\%); relatives/friends (49\%); someone with a joint problem (41\%) and pharmacists (37\%). Conclusions: Less than half of the current sample would seek help quickly for the symptoms of RA. Several barriers and drivers identified in qualitative research ${ }^{3}$ were endorsed by the survey sample making them valid targets for interventions Most participants would further seek out information about the symptoms prior to seeking medical attention and their preferred sources of information such as the internet or the pharmacist should be used in these targeted interventions.

\section{REFERENCES:}

[1] Raza K, Filer A. The therapeutic window of opportunity in rheumatoid arthritis: does it ever close? Ann Rheum Dis 2015;74:793-4.

[2] Stack RJ, et al. Patient delays in seeking help at the onset of rheumatoid arthritis: the problem, its causes and potential solutions. Aging Health 2013;9:425-35.

[3] Simons G, et al. A qualitative investigation of the barriers to help-seeking among members of the public presented with symptoms of new-onset rheumatoid arthritis. J. Rheumatol 2015;42:585-92.

Acknowledgements: This research was supported by The Dunhill Medical Trust (grant number R226/1111) and the National Institute for Health Research, through the Primary Care Research Network. CDM is funded by the NIHR CLAHRC West Midlands, the NIHR School for Primary Care Research and a NIHR Research Professorship in General Practice (NIHR-RP-2014-04-026). KR is funded by the Birmingham NIHR BRC. The authors would like to thank the patient research partners who have been involved in the project.

Disclosure of Interest: None declared

DOI: 10.1136/annrheumdis-2018-eular.2529

\section{THU0651}

THE INFLUENCE OF AGE, GENDER, EMPLOYMENT STATUS, OR EDUCATION ON THE CHOICE OF BIOSIMILAR VS. BIO-ORIGINAL VARIANT OF THE SAME BDMARD IN PATIENTS WITH RA OR AS STARTING BIOLOGICAL THERAPY - REAL LIFE DATA FROM THE CZECH BIOLOGICS REGISTRY ATTRA

J. Zavada ${ }^{1}$, L. Nekvindova ${ }^{2}$, K. Pavelka ${ }^{1}$, J. Vencovsky ${ }^{1}$, on behalf of collaborators of the ATTRA registry. ${ }^{1}$ INSTITUTE OF RHEUMATOLOGY, Prague; ${ }^{2}$ Instititute of Biostatistics and Analyses spinn-off, Faculty of Medicine, Masaryk University, Brno, Czech Republic

Background: Perceptions on bio-originator (bo) and bio-similar (bs) biologics among HCPs and pts, as well administrative regulations or economic incentives may influence their utilisation in clinical practice. The ATTRA registry captures more than $95 \%$ of pts with RA and AS treated with biologics in the Czech Republic (CZ). Access to biological therapy in CZ is limited to about 30 authorised centres. Bs infliximab (INF) has been prescribed in CZ since 11/2013, and bs etanercept (ETA) since 1/2016 concurrently with bo INF and ETA. There has been no administrative regulation concerning the use of bs or bo in $\mathrm{CZ}$.

Objectives: To explore whether age, gender, employment status, or level of education influence the choice of bs vs. bo variant of the same bDMARD in pts with RA or AS starting bDMARD in CZ.

Methods: Data from the ATTRA registry on pts with RA or AS starting their first bDMARD between 11/2013 and 10/2017 were used. The start of bo vs. bs ETA or bo vs. bs INF as the first bDMARD was the main outcome of interest. Multivariate logistic regression analysis was used to explore the impact of education employment status, age and gender on the start of a first bDMARD after adjustment for disease characteristics, and the bDMARD molecule.

Results: 560 pts started ETA ( $22.6 \%$ bo, $14.2 \%$ bs $)$ or INF $(9.7 \%$ bo, $53.5 \%$ bs $)$ in the study time frame. In the multivariate model (table 1) pts starting ETA (ref. INF) had lower odds to receive a bs (OR $0.11, \mathrm{CI} 95 \% 0.07-0.17$ ), and pts with primary education (vs. secondary or tertiary) had higher odds to receive any bs (OR 1.84 CI95\% 1.08-3.13). When we performed separate analyses for pts treated in academic/public hospitals $(n=314)$, the adjusted OR for pts with primary education was $0.78(\mathrm{Cl} 95 \% 0.37-1.64)$, while in private centres $(n=246)$ the OR was 5.32 (CI 95\% 2.32-12.16). When we introduced an interaction term for type of practice $x$ level of education, the adjusted OR for pts with primary education in private centres was $2.26(\mathrm{Cl} 95 \%, 1.14-4.46, \mathrm{p}=0.019)$.

Abstract THU0651 - Table 1.

\begin{tabular}{lcc}
\hline Parameters & OR $(95 \% \mathrm{Cl})$ & p-value \\
\hline HDA vs. REM+LDA+ MDA (acc to DAS28/ASDAS) & $0.94(0.50 ; 1.77)$ & 0.859 \\
CRP [mg/l] & $1.00(0.99 ; 1.01)$ & 0.770 \\
HAQ & $1.16(0.75 ; 1.78)$ & 0.513 \\
AS (vs. RA) & $1.40(0.81 ; 2.40)$ & 0.229 \\
ETA (vs. INF) & $0.11(0.07 ; 0.17)$ & $<0.001$ \\
Age at start of 1st bDMARD & $1.01(0.99 ; 1.04)$ & 0.271 \\
Disease duration & $1.01(0.98 ; 1.04)$ & 0.693 \\
Female & $0.78(0.48 ; 1.26)$ & 0.316 \\
Primary education (vs. Secondary or Tertiary) & $1.84(1.08 ; 3.13)$ & $\mathbf{0 . 0 2 4}$ \\
Sick leave (vs. employed) & $1.61(0.68 ; 3.82)$ & 0.283 \\
Disability pension (vs. employed) & $0.74(0.36 ; 1.54)$ & 0.421 \\
Old age pension (vs. employed) & $0.61(0.28 ; 1.31)$ & 0.205 \\
Unemployed (vs. employed) & $1.08(0.48 ; 2.42)$ & 0.845 \\
Maternity leave/student (vs. employed) & $1.48(0.43 ; 5.08)$ & 0.529 \\
\hline
\end{tabular}

Conclusions: We found that in private centres providing biological therapy in $\mathrm{CZ}$, pts with primary education had higher adjusted odds to obtain bs as the first bDMARD. We cannot exclude that different pt characteristics and residual confounding may have been involved. The interpretation is complex and related not only to perception of bs by HCPs and pts, but also to unmeasured economic incentives and other factors.

Acknowledgements: This work was supported by the project (Ministry of Health, Czech Republic) for consensual development of research organisation 023728 Disclosure of Interest: None declared

DOI: 10.1136/annrheumdis-2018-eular.5559 